\title{
IMPACTO DO DANO DA MOSCA DO SORGO, Contarinia sorghicola (COQUILLETT 1898), NO PESO DE CADA GRĀO REMANESCENTE À INFESTAÇĀO.
}

\section{RESUMO}

$O$ efeito do dano da mosca do sorgo, Contarinia sorghicola (Coq.) no peso de 100 grãos remanescentes à infestação de panícula infestada foi avaliado em dois híbridos de sorgo (um resistente e um susceptível a esta praga).

A diferença do peso de 100 grãos provenientes de panículas com diferentes proporções de espiguetas danificadas pela mosca $(0$ a 100\%) foi da ordem de 10 e $20 \%$ respectivamente para o híbrido resistente e susceptível". Foi observado uma baixa correlação entre o peso de 100 grãos e outros parâmetros como: comprimento, diâmetro e peso da panícula; peso total de grãos e danos da mosca. Entretanto, nos dois híbridos, a distribuição das médias do peso de 100 grãos provenientes de panículas com diferentes proporções de espiguetas danificadas pela mosca aproximou-se de uma função quadrática. $O$ peso máximo de 100 grãos ocorreu quando as panículas estavam com 40 e $50 \%$ de espiguetas danificadas pela mosca respectivamente para o híbrido susceptível e resistente. Isto indica que em panículas şob leves infestações há uma pequena compensação do dano produzindo maiores grãos e sob severa infestação há redução do peso individual dos grãos, que escapam a infestação. Entretanto, esta compensação do dano da mosca não é suficiente para recuperar a perda causada diretamente às espiguetas infestadas.

\section{THE IMPACT OF SORGHUM MIDGE DAMAGE ON THE WEIGHT OF SURVIVING KERNELS}

\section{ABSTRACT}

The effect of sorghum midge damage on the weight of surviving kernels from infested panicles of two sorghum hybrids (one resistant and other susceptible to this pest) was evaluated. The difference of 100 kernels weight from panicles with 0 to $100 \%$ of grain damage was repectively 10 and $20 \%$ to the resistant and susceptible hybrid. There was a low correlation between the weight of 100 kernels and others parameters like: lenght, diameter and weight of the panicle; total weight of grain and midge damage. However, for both hybrids, the mean distribution of 100 kernels weight of panicles with $10 \%$

1 Pesquisador-PhD, CNPMS/EMBRAPA, Caixa Postal 151, CEP 35700, Sete Lagoas, MG.

2 Professor of Entomology-PhD, Department of Entomology, Texas A \& M University, College Station, TX. 77843, USA. 
spikelets damage intervals was a quadratic function. The maximum 100 kernels weight was respectively with 40 e $50 \%$ of midge damaged spikelets to the susceptible and resistant hybrid. The results indicated that: there is a little compensation by the surviving kernels in panicles with low proportion of midge damaged spikelet, but there is a weight lost by surviving kernels in panicles with high proportion of midge damaged spikelets. However, this compensation is not enought to recuperate the direct damage caused by the sorghum midge to the infested spikelets.

\section{INTRODUÇÃO}

Desde 1967 a mosca do sorgo, Contarinia sorghicola (Coquillett, 1898), vem sendo citada como um fator limitante para a cultura do sorgo no Brasil. A obtenção de cultivares de sorgo resistentes é o método de controle dessa praga que tem recebido maior atenção por parte dos pesquisadores. Resistência de sorgo à mosca tem sido reportada por Walter (1941), Geering (1953), Bowden \& Neve (1953), Bowden (1965), Rossetto \& Banzatto (1967), Wiseman \& McMillian (1968), Johnson et al. (1973), Parodi et al. (1974), Page (1979), Wuensche (1980) e Busoli (1980). Hoje, já se sabe que o principal mecanismo de resistência de sorgo à mosca é não-preferência para oviposição (Rossetto 1977) e Waquil et al. (1986 a,b). Tanto nos materiais resistentes quanto nos susceptíveis, o desenvolvimento de uma única larva numa espigueta é suficiente para danificar irreversivelmente o grão (Waquil 1985). Entretanto, numa mesma panícula o reflexo da infestação de algumas espiguetas, no peso dos grãos remanescentes à infestação, permanece controvertido. Harris (1961) não encontrou relação entre o grau de infestação da panícula de sorgo pela mosca e a massa dos grãos provenientes de espiguetas da mesma panícula (que escaparam à infestação). Entretanto, Montoya (1965) e Doggett (1970) mencionam que uma pequena compensação de perda ocorre nos grãos provenientes de espiguetas que escapam à infestação pela mosca.

Recentemente, Hallman et al. (1984) estudaram a relação entre o peso dos grãos remanescentes à infestação e o nível de infestação da mosca do sorgo na panícula. Estes autores verificaram que em panículas com mais de $40 \%$ de infestação, há uma redução do peso de $\mathbf{4 0}$ grãos e que a esterilização artificial de espigueta resulta em compensação pelos grãos remanescentes à infestação. Eles citam o trabalho de Fischer e Wilson onde a remoção manual de até $1 / 3$ das espiguetas do sorgo na fase de florescimento não resulta em redução do peso total de grãos, o que indica uma compensação em peso pelos grãos produzidos nas espiguetas não removidas.

O objetivo deste trabalho foi verificar o impacto da infestação da mosca no peso individual dos grãos remanescentes à infestação de panículas de sorgo infestadas desde 0 a próximo de $100 \%$.

\section{MATERIAL E MÉTODOS}

Em 1984 foi instalado um experimento em blocos casualizados com 5 repetições contendo 2 parcelas de 4 linhas de $6 \mathrm{~m}$, na fazenda experimental da Texas A \& M University em College Station, Texas. Nas parcelas foram plantados dois híbridos de sorgo, um resistente à mosca (AT×2755 x TX 2767) e outro susceptivel (AT×2752 x TX 430).

$\mathrm{Na}$ fase de emborrachamento das plantas, cerca de 10 panículas por parcela foram protegidas com sacolas de tela plástica para evitar a infestação pela mosca. $\mathrm{Na}$ fase de florescimento, as plantas não protegidas foram naturalmente infestadas e na fase de grãos leitosos, 15 panículas, de mesmo porte por parcela, foram etiquetadas segundo sua classe de dano. Os níveis de infestação das panículas de sorgo pela mosca foram estimados 
visualmente segundo uma escala de notas que varia desde 0 (zero \% de infestação), até 10 (95 a 100\% de infestação). Após a maturação, as panículas foram colhidas, avaliadas e triIhadas individualmente. Foram anotados o comprimento, diâmetro e peso de cada panícula; peso total de grãos da panícula e peso de 100 grãos (após o equilíbrio da umidade entre as amostras). Os 100 grãos foram contados num contador eletrônico onde manualmente foram eliminados os grãos com qualquer tipo de defeito como grã́os quebrados, doentes, etc.

Os dados obtidos foram submetidos à análise estatística por diferentes métodos. Foi feita a análise de variância para comparar o peso de 100 grãos provenientes de cada classe de dano e uma correlação entre este e os parâmetros da panícula tais como: peso, comprimento, diâmetro e peso total de grãos. Finalmente, procedeu-se uma análise de regressão para os diferentes níveis de infestação das panículas e o peso de 100 grãos.

\section{RESULTADO E DISCUSSÃO}

A análise estatística dos dados do peso de 100 grãos mostrou que o modelo matemático envolvendo blocos, híbridos, classes de dano e interação (híbrido x classes de dano), foi altamente significativo ( $P<0,01 \%)$. Da mesma forma, o efeito de híbridos e classes de dano foi significativo ( $P<0,01 \%$ ). Entretanto, a interação foi significativa somente ao nível de $94 \%$ de probabilidade (Tabela 1). Mesmo assim, decidiu-se analisar os efeitos das classes de danos no peso de 100 grãos para cada híbrido separadamente. O híbrido resistente possui o peso de 100 grãos significativamente $(P<0,01 \%)$ menor que o híbrido susceptível à mosca.

TABELA 1. Análise de variância do peso de 100 grãos provenientes de panículas de sorgo com infestações variando de 0 a $100 \%$.

\begin{tabular}{lrrr} 
C.V. & GL. & $F$ & P (\%) \\
\hline MODELO & 256 & 9,23 & 0,01 \\
RESIDUO & 13 & & \\
TOTAL & 161 & & 22,87 \\
\hline Blocos & 4 & 1,43 & 0,01 \\
Hybridos & 1 & 109,24 & 0,01 \\
Classe de dano & 10 & 6,05 & 5,97 \\
INTERAÇÃO & 10 & 1,84 &
\end{tabular}

$\mathrm{R}^{2}=0,63$

C.V. $=9,53$

Para se avaliar a eficiência da padronização das panículas durante a avaliação das classes de infestação, fez-se a correlação de vários parâmetros com o peso de 100 grãos (Tabela 2). Sabe-se que o vigor da planta de sorgo é bastante afetado pela densidade e consequentemente grande variação nas panículas aumentaria o erro experimental. A correlação entre o peso de 100 grãos e comprimento da panícula foi praticamente nula. Em- 
bora as demais correlações tenham sido significativas, exceto para as classes de danos e o peso de 100 grãos, elas foram muito baixas.

Se a infestação das panículas de sorgo afetasse o peso de 100 grãos num só sentido (aumentando ou reduzindo o grão) conforme a literatura indica, ésperava-se uma alta correlação (positiva ou negativa) entre esses dois parâmetros. Entretanto isto não ocorreu. Portanto, esta hipótese deve ser rejeitada.

\section{TABELA 2. Coeficientes de correção $r$ entre parâmetros da panícula e peso de 100 grãos. College Station 1985.}

Comprimento da panícula

Diâmetro da panícula

Peso da panícula

Peso total de grãos da panícula

Notas de dano de mosca

A aplicação do geste de $t$ indicou diferenças significativas $(P<0,01 \%$ ) entre as médias do peso de 100 grãos proveniente de cada classe de dano da mosca na panícula (Fig. 1). Nota-se que a distribuição das médias para ambos híbridos indica uma função quadrática cuja análise de Regressão indicou significância ao nível de 0,26\% de probabilidade (Fig. 2).

Para o híbrido de sorgo resistente à mosca, a função quadrática estimada indica o peso máximo de grão (peso 100 grãos) em panículas com aproximadamente $50 \%$ de infestação (Fig. 2). Já para o híbrido susceptível, este máximo ocorreu na faixa dos $40 \%$ de infestação (Fig. 3). Estes resultados sugerem que em panículas de sorgo sob leve infestação da mosca há uma pequena compensação do dano da mosca através de um maior peso individual dos grãos remanescentes à infestação. Por outro lado, em panículas sob alta infestação, há uma redução do peso individual dos grãos remanescentes à infestação, acarretando ainda uma maior perda do que a estimada pelo dano direto (chochamento de espiguetas). Este fato foi evidente no híbrido susceptivel. Entretanto, no híbrido resistente a curva foi quase simétrica onde o peso estimado para 100 grãos provenientes de panículas com notas 0 e 10 foi muito próximos.

Há algumas evidências que podem ajudar a explicar esses resultados. Nas condições estudadas, o pico de emergência de adultos da mosca no híbrido susceptível, ocorreu aproximadamente 16 dias após a infestação. Por outro lado, o período de enchimento de grão no sorgo é de aproximadamente 30 dias (House 1982). Independente do híbrido ser resistente ou susceptível, cerca de $85 \%$ dos ovos da mosca são depositados na.flor do sorgo durante a antese (Waquil 1985). Sob leves infestações, é pouco provável a múltipla oviposição (mais de 1 ovo por flor) e somente uma larva se desenvolve em cada espigueta. Portando, é possível que uma larva da mosca alimentando-se do cariopse por cerca de 10 dias (período larval) não consome todo o material que seria armazenado naquele grão e provoca a morte deste. Consequentemente, há o efeito de esterilização dessa espigueta favorecendo um maior acúmulo de material nas espiguetas não infestadas (Hallman 1984). 


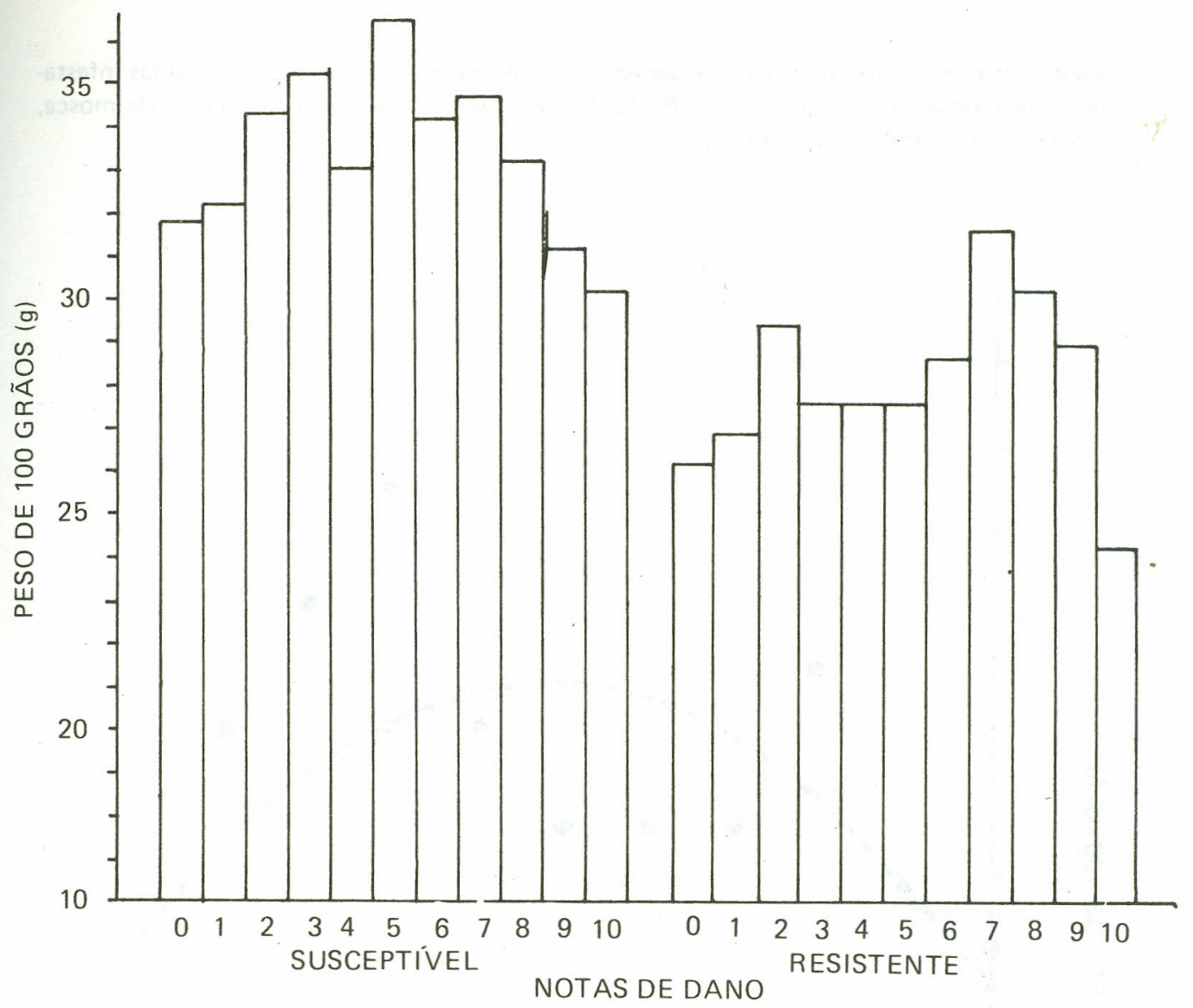

FIG. 1. Peso médio de 100 grãos (g) de sorgo provenientes de panículas com diferentes níveis de danos causados pela mosca de sorgo.

No caso de altas infestações pela mosca, até 7 larvas desenvolvem em uma espigueta através de múltipla oviposição (Waquil 1985). Neste caso, há a drenagem de muito mais material do que seria acumulado naquele grão da espigueta infestada e ocorre uma significativa redução no peso dos grãos que escapam à infestação. Os dados aparentemente contraditórios para o peso individual de grãos, apresentados na literatura, podem ser resultados de observações provenientes de panículas de diferentes extremos de infestação e portanto, coerentes com os dados aqui apresentados.

No híbrido de sorgo resistente à mosca, o peso de 100 grãos estimado pela curva não revela redução de peso, mesmo sob alta infestação da panícula. Normalmente, o peso de 100 grãos do híbrido resistente é menor que do híbrido susceptível. Também, a frequência de esteribilidade naturạl é um pouco mais alta no híbrido resistente. A proporção de indivíduos da mosca que completa o ciclo no híbrido resistente é menor que no híbrido susceptível e há diferenças entre os híbridos na posição que as larvas desenvolvem dentro da espigueta (Waquil 1985). Portanto, é possível que este híbrido tenha algum mecanismo de defesa contra o efeito de redução do peso individual dos grãos que escapam à infestação.

Mesmo havendo compensação pelos grãos remanescentes à infestação, ela é insuficiente para recuperar toda a perda ocorrida nas espiguetas infestadas. Consequentemente, há redução do peso total de grãos da panícula mesmo sob baixas infestações (Fig. 4). A 
redução do peso total de grãos da panícula não é linear ao número de espiguetas infesta- das pela mosca, mas é quadrática. Portanto, por menor que seja a infestação da mosca, sempre ocorre perda na produção.

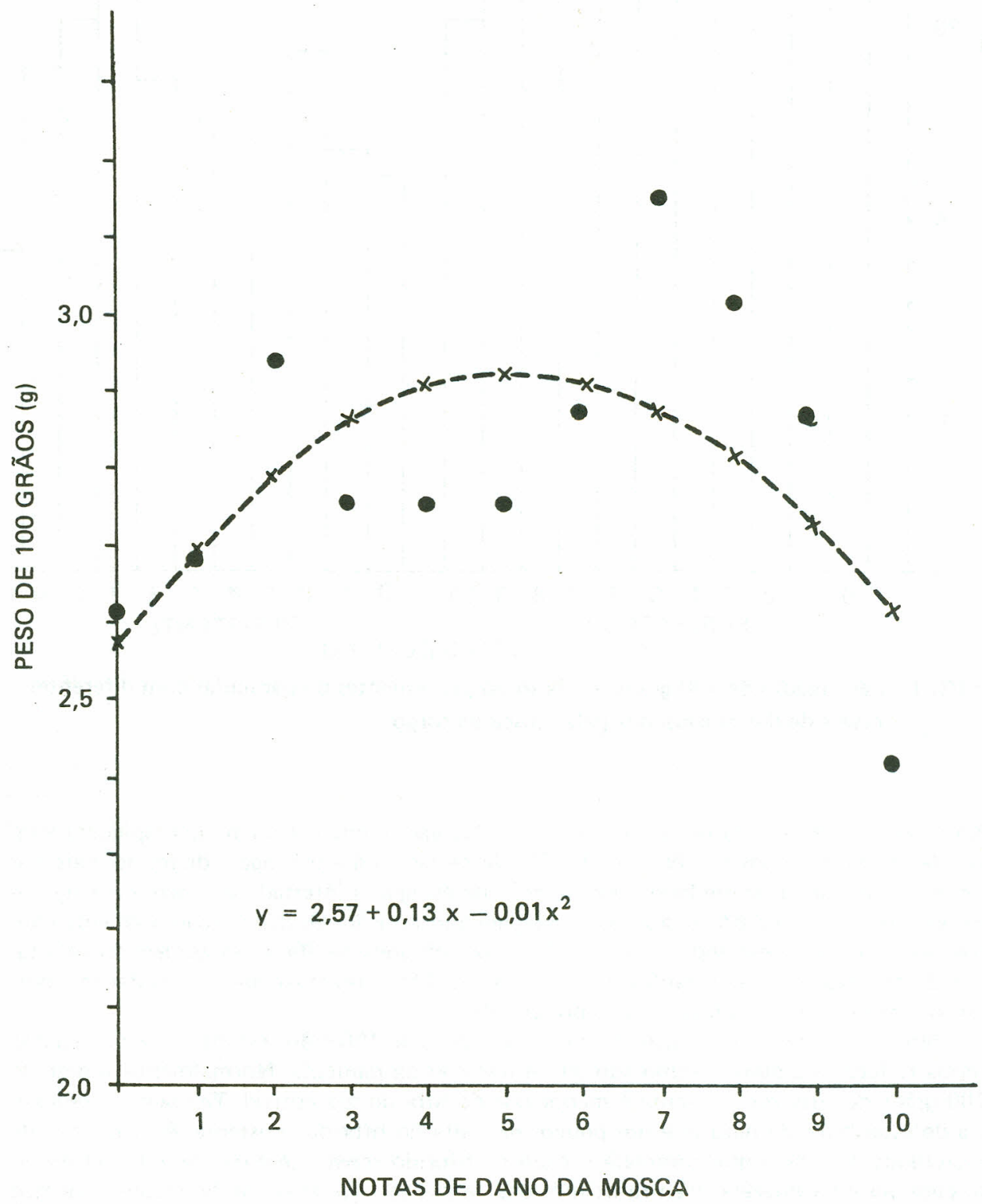

FIG. 2. Estimativa do peso de $\mathbf{1 0 0}$ grãos (g) provenientes de panículas do híbrido de sorgo resistente à mosca e sob diferentes níveis de danos. College Station, Tx. 1984. 


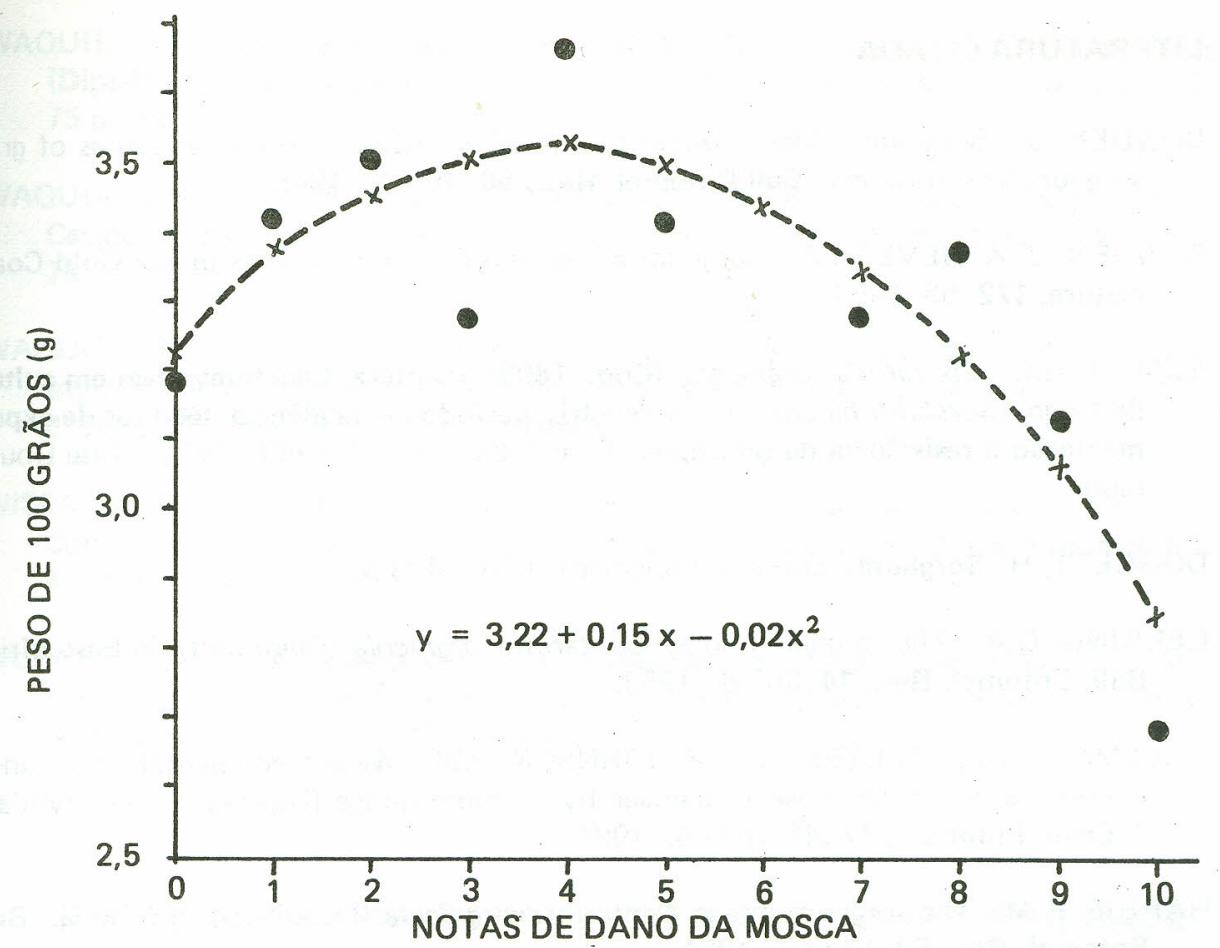

FIG. 3. Estimativa de peso de 100 grãos (g) provenientes de paniculas de híbrido de sorgo susceptível à mosca e sob diferentes níveis de danos. College Station, Tx. 1984.

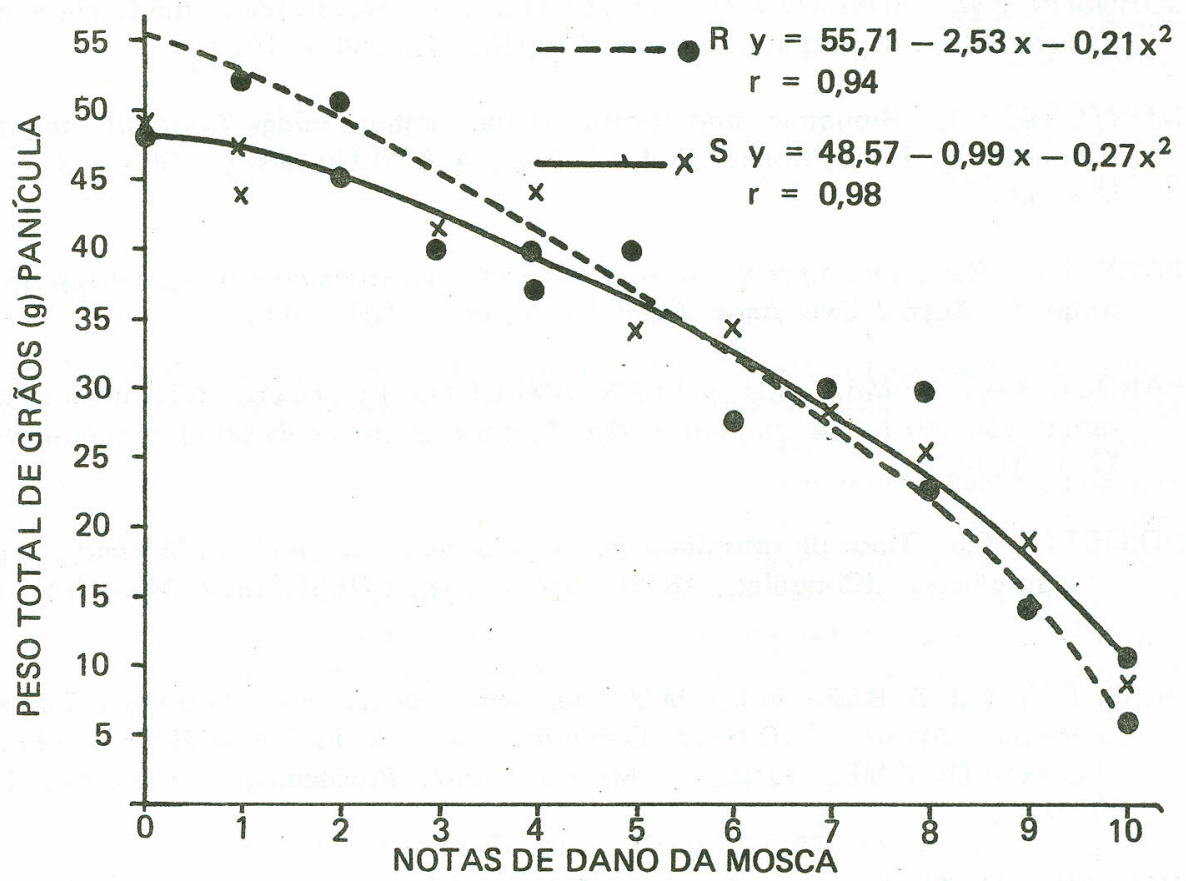

FIG. 4. Peso total de gråos $(g)$ de panículas de sorgo sob diferentes níveis de infestação pela mosca. College Station, Tx. 1985. 


\section{LITERATURA CITADA}

BOWDEN, J. Sorghum midge, Contarinia sorghicola (Coq.), and other causes of grain sorghum loss in Ghana. Bull Entomol. Res., 56: 169-89, 1965.

BOWDEN, J. \& NEVE, R.A. Sorghum midge and resistant varieties in the Gold Coast. Nature, 172: 55, 1953.

BUSOLI, A.C. Contarinia sorghicola (Coq., 1898) (Diptera: Cecidomyiidae) em cultura de sorgo [Sorghum bicolor (L.) Moench]: período de incidência, técnicas de experimentação e resistência de genótipos. Piracicaba, ESALQ, 1980. 157 p. Tese Doutorado.

DOGGETT, H. Sorghum. London, Longmans, 1970. 403 p.

GEERING, Q.A. The sorghum midge. Contarinia sorghicola (Coquillett), in East Africa. Bull. Entomol. Res., 14:363-6. 1953.

HALLMAN, G.J.; TEETES, G.L. \& JOHNSON, J.W. Weight compensation of undamaged kernels in response to damage by sorghum midge (Diptera: Cecidomyiidae). J. Econ. Entomol., 77 (4): 1033-6. 1984.

HARRIS, K.M. The sorghum midge Contarinia sorghicola (Coquillett) in Nigéria. Bull. Entomol. Res., 52: 129-46. 1961.

HOUSE, L.R. A Guide to Sorghum Breeding. Patancheru, ICRISAT, 1982. 238 p.

JOHNSON, J.W.; ROSENOW, D.T. \& TEETES, G.L. Resistance to the sorghum midge in coverted exotic sorghum cultivars. Crop Sci., 13: 754-5. 1973.

MONTOYA, E.L. Bionomics and control of the sorghum midge Contarinia sorghicola (Coquillett). Texas, Co!lege Station, Texas A \& M University, 1965. 43 p. Tese Mestrado.

PAGE, F.D. Resistance to sorghum midge [Contarinia sorghicola (Coquillett)] in grain sorghum. Aust. J. Exp. Agric. Anim. Husb., 19: 97-101. 1979.

PARODI. R.A.; GAMBA, R.D. \& SCANTAMBURLO, J.L. Huerin INTA grain sorghum variety tolerant to the sorghum midge (Contarinia sorghicola Coq.) Sorghum Newsl, 17: 1.1974.

ROSSETTO, C.J. Tipos de resistência de sorgo, Sorghum bicolor (L.) Moench, a Contarinia sorghicola (Coquillett, 1898). Jaboticabal, UNESP, 1977. 34 p. Tese Livre Docente.

ROSSETTO, C.J. \& BANZATTO, M.V. Resistência de variedade de sorgo a Contarinia sorghicola (Coquillett) (Diptera: Cecidomyiidae). In: LATIN AMERICAN PLANT TECHNOLOGY MEETTING, 7., Maracay, 1967. Proceedings... Maracay, 1967. $592 \mathrm{p}$.

WALTER, E.V. The biology and control of the sorghum midge. Washington, USA, 1941. 26 p. (Tech. Bull., 778). 
WAQUIL, J.M. Resistance modality of resistant hybrid sorghum to sorghum midge (Diptera: Cecidomyiidae). Texas, College Station, Texas A \& M University, 1985. 75 p. Tese Doutorado.

WAQUIL, J.M.; TEETES, J.L. \& PETERSON, G.C. Adult sorghum midge (Diptera: Cecidomyiidae) nonpreference for a resistant hybrid sorghum. J. Econ. Entomol., 79 (2): 455-8. 1986a.

WAQUIL, J.M.; TEETES, G.L. \& PETERSON, G.C. Sorghum midge (Diptera: Cecidomyiidae) adult ovipositional behavior on resistant and susceptible sorghum hybrids. J. Econ. Entomol., 72(2): 530-2. $1986 \mathrm{~b}$.

WISEMAN, B.R. \& MCMILLIAN, W.W. Resistance in sorghum to the sorghum midge, Contarinia sorghicola (Coquillett) (Diptera: Cecidomyiidae). J. Ga. Entomol. Soc., 4: 15-22. 1968.

WUENSCHE, A.L. An assessment of plant resistance to the sorghum midge, Contarinia sorghicola, in selected lines of Sorghum bicolor. Texas, College Station, Texas A \& M University, 1980. 193 p. Tese Doutorado.

\title{
SITUAÇĀO DO ARMAZENAMENTO A NIVEL DE PROPRIEDADE NO ESTADO DO ESPIRITO SANTO
}

\author{
Jamilton P. Santos ${ }^{1}$ \\ Renato A. Fontes ${ }^{1}$ \\ Ivan V.M. Cajueiro ${ }^{2}$ \\ José R. Arleu ${ }^{3}$ \\ Cesar Fanton ${ }^{3}$ \\ Maurício Fornazier ${ }^{3}$
}

\section{RESUMO}

Um questionário, enfocando os principais aspectos da armazenagem de milho no meio rural, foi respondido por 221 produtores distribuídos pelas principais regiões produtoras do Estado do Espírito Santo. Foi constatado que 68\% das propriedades possuem área inferior a 35 ha, o que caracteriza o Estado como predominantemente de pequenos produtores. $\mathrm{O}$ milho é colhido manualmente e a colheita está concentrada nos meses de março e abril. Entre os produtores de milho, $43 \%$ armazenam e consomem em suas propriedades todo o milho que prodúzem, $56 \%$ armazenam toda a produção, porém comercializam uma parte na entressa e $1 \%$ planta milho exclusivamente para comercializar e o faz logo após a colheita. 0 armazenamento em espiga com palha é utilizado por $85 \%$ dos

1,2 Eng?s Agrọs e Biólogo. Pesquisadores do CNPMS/EMBRAPA - Caixa Postal 151 CEP 35700 - Sete Lagoas - MG.

3 Eng?s Agr?s Pesquisadores da EMCAPA - CEP 29000 - Vitória - ES. 